\section{O DEVER DE REALIZAR O MAL}

\section{THE DUTY OF DOING THE EVIL}

\author{
ALEXANDRE NORONHA MACHADO ${ }^{1}$
}

(Universidade Federal do Paraná, Brasil)

\begin{abstract}
Aqui, o fato fundamental é que nós estabelecemos regras, uma técnica para jogar um jogo, e que então, quando seguimos as regras, as coisas não saem como tínhamos suposto. Assim que estamos, por assim dizer, emaranhados em nossas próprias regras.

Este emaranhamento em nossas regras é o que queremos entender: isto é, inspecionar. (WITTGENSTEIN, 1958, §125)
\end{abstract}

\section{RESUMO}

O texto que se segue consiste na apresentação de um problema filosófico, no exame e crítica de algumas possíveis maneiras de tentar solucioná-lo e na apresentação do que julgo ser sua melhor solução (aristotélica). Trata-se de um problema em filosofia moral ou ética, como o titulo já deixa claro. Este, portanto, não é um texto exegético sobre a filosofia de Wittgenstein. Mas creio que ele deve muito à filosofia tardia de Wittgenstein por duas razões principais. O problema filosófico apresentado aqui é entendido como uma confusão gramatical envolvendo o uso de termos morais. Além disso, a solução aqui proposta é obtida por meio da análise do uso ordinário desses termos. (cf. WITTGENSTEIN, §§109-111)

Palavras-chave: Ética. Mal. Wittgenstein. Aristóteles.

\begin{abstract}
In this paper I lay down a philosophical problem, I examine and criticise some possible attempts to solve it and I argue for what I believe to be its best solution. This is a philosophical problem in moral philosophy or ethics, as the title already makes it clear. Therefore this is not an exegetical paper about Wittgenstein's philosophy. However, I think it is in debt with Wittgenstein's late philosophy for two main reasons: the philosophical problem laid down here is understood as a grammatical confusion involving the use of some moral terms. Besides, the solution argued for here is reached through the analysis of the ordinary use of these terms. (cf. WITTGENSTEIN, $\S \S 109-111$ )
\end{abstract}

Key Words : Ethics. Evil. Wittgenstein. Aristotle.

\section{0 problema}

Frequentemente o pensamento de que este mundo não é o melhor dos mundos possíveis toma nossa mente de assalto. Uma das razões para que esse pensamento nos 
pareça verdadeiro é o fato que, frequentemente, a melhor coisa a fazer em determinada circunstância, de um ponto de vista moral, é algo que consideramos intrinsecamente mau, ou um mal em si mesmo. Por exemplo: há circunstâncias em que a melhor coisa a fazer para salvar a vida de uma pessoa que não merece morrer é matar aquela outra pessoa que ameaça a sua vida. Matar alguém parece um mal em si justamente porque gostaríamos que ninguém precisasse fazer isso em circunstância alguma e que ninguém desejasse ter de fazer isso. A existência de tais circunstâncias no mundo atual parece denunciar a sua imperfeição, porque podemos imaginar um mundo aparentemente possível em que não há nenhuma circunstância em que fazer isso é o melhor a fazer; um mundo em que não somos jamais obrigados pelas circunstâncias a realizar uma ação que julgamos ser intrinsecamente má.

Sob um exame mais cuidadoso, essa aparente imperfeição do mundo atual parece um problema ainda maior, pois ela parece fazer algumas de nossas intuições sobre o bem e o mal moral se chocarem. Imagine que uma pessoa seja a tal ponto desafortunada que, em todas as circunstâncias em que ela precisa agir, o melhor a fazer é sempre algo intrinsecamente mau. Essa pessoa faz apenas o que é um mal em si. Ela é boa ou má? Parece absurdo dizer que ela é má, dado que ela sempre faz o que é melhor em cada circunstância. Ela sempre delibera de modo moralmente excelente. O melhor a se fazer em cada circunstância do ponto de vista moral parece se identificar com aquilo que moralmente devemos fazer, com o dever moral. Portanto, esta pessoa cumpre com o seu dever moral em todas as circunstâncias. Todavia, como ela pode ser uma boa pessoa, se em todas as circunstâncias ela realiza aquilo que é um mal em si? Uma boa pessoa não é aquela que realiza o bem? Como realizar sempre ações em si mesmas más pode ser ao mesmo tempo a realização do dever moral?

Quero chamar esse problema de problema do dever de realizar o mal. ${ }^{2}$ Não quero entrar na discussão sobre se o mundo atual é ou não o melhor dos mundos possíveis. O entendimento do problema que quero discutir não depende de uma resposta a esta pergunta. Para esse entendimento, basta que se admita que nem todos os mundos possíveis são igualmente desejáveis do ponto de vista moral, ou seja, que alguns deles são melhores que outros. O entendimento do problema do dever de realizar o mal também não supõe a tese que dizer de um mundo possível que ele é moralmente melhor que outro implica que ele é absolutamente melhor, ou seja, melhor em todos os seus aspectos morais. Um mundo possível pode ser dito moralmente melhor que outro em 
relação a um aspecto moral, mesmo que seja igual ou pior em relação a outros. Digo isso também para evitar a objeção de inspiração espinosiana segundo a qual mesmo que um mundo contenha o que julgamos ser um mal em si, no cômputo geral ele pode ser melhor que um mundo que não o contenha. A formulação do problema do dever de realizar o mal depende apenas de que nos restrinjamos àquilo que ordinariamente julgamos saber sobre o mundo atual e outros mundos possíveis no que respeita a seus aspectos morais. Por isso, dizer que não se sabe se o mundo A é melhor ou pior que o mundo B em relação a um certo aspecto porque isso só poderia ser decidido no cômputo geral de que não dispomos não é uma objeção aceitável. Quando lutamos por um mundo melhor, o fazemos baseados na escolha de aspectos particulares que esse mundo melhor deve ter e de aspectos particulares que ele não deve ter. Pergunte-se, baseado no que julgas saber, se tens alguma dúvida racional sobre se é moralmente desejável em si mesmo o homicídio de uma pessoa, por exemplo. Pergunte-se se não vês nenhum problema moral em uma pessoa que tem prazer de ser carrasco, em uma sociedade em que há pena legal de morte, tão somente porque, dessa forma, ela pode cometer um homicídio legalmente, não tendo nenhum interesse na justiça.

\section{Algumas tentativas de solução: purismo moral, casuísmo e finalismo}

Há um tipo de posição extrema em filosofia moral, o purismo moral, que lida com esse problema inicialmente aceitando que o conflito das nossas intuições morais descrito acima é real: para o purista moral é incompatível que alguém esteja realizando o bem quando está realizando algo que é um mal em si mesmo. A solução proposta é a tese que só se realiza o bem quando a ação que realizamos é um bem em si. Um purista moral que quer realizar o bem e acredita que matar é um mal em si, portanto, não mataria uma pessoa que está ameaçando a vida de outra para salvar a vida dessa última. Um purista moral acredita que o âmbito daquilo que é um mal em si restringe o âmbito de ações moralmente justificadas em quaisquer circunstâncias: nenhuma ação que seja um mal em si pode ser moralmente justificada, seja qual for a circunstância de ação que se considere. Para o purista moral, o bem moral é um bem absoluto, sempre independente das circunstâncias. (Não devemos confundir o bem ou mal absolutos com o que é bem ou um mal em si. Isso ficará mais claro na próxima seção.)

Uma outra posição extrema em filosofia moral, que vou chamar de casuísmo, lida com o problema do dever de realizar o mal também aceitando que o conflito entre as 
nossas intuições morais que constituem esse problema é mesmo real: para o casuísta é incompatível que alguém esteja realizando o bem quando está realizando algo que é um mal em si mesmo. Porém, ao contrário do purista moral, o casuísta procura solucionar esse conflito negando que haja algo que seja um bem ou um mal em si mesmo. Para ele, todo bem moral e todo mal moral é relativo às circunstâncias da deliberação moral. Para um casuísta, nem matar, nem mentir, por exemplo, são um mal em si. Ser um mal é sempre relativo às circunstâncias em que se delibera. Se o melhor a fazer em determinada circunstância é matar, então, nessa circunstância, matar é um bem moral. A máxima generalização que podemos obter a partir dessa deliberação particular é que matar é um bem em qualquer circunstância igual a essa.

Há quem tente uma posição intermediária, mais plausível, entre o purismo moral e o casuísmo. Segundo essa posição, matar, por exemplo, é um mal em si em qualquer circunstância. Todavia, o bem moral que se realiza, no caso descrito acima, é salvar a vida de uma pessoa que não merece morrer. Portanto, essa pessoa realizou um bem moral porque realizou algo que é um bem em si: salvar a vida de alguém que não merece morrer. É por isso que ela, nessa circunstância, é uma boa pessoa, não por ter matado alguém. E é por isso que ela será em geral uma boa pessoa se realizar em geral o que é o bem em si, não por realizar em geral o que é o mal em si. Vou chamar essa posição em filosofia moral de finalismo. Essa é uma tentativa de mostrar que não é incompatível que alguém esteja realizando o bem quando está realizando algo que é um mal em si mesmo. Ela realiza, de fato, algo que é um mal em si. Mas esse não é o bem que ela realiza. Ela somente realiza um bem se realiza algo que é um bem em si. E isso que é um bem em si não o deixa de ser somente porque na mesma circunstância ela realiza um mal em si.

$\mathrm{Eu}$ estou de acordo com o finalismo sobre o seguinte: o conflito entre as nossas intuições que constitui o problema do dever de realizar o mal é apenas aparente. Mas não acho que o finalismo resolva o problema. A solução do problema, se parte da suposição que o referido conflito é apenas aparente, deveria mostrar que é possível que a realização de uma certa ação em uma certa circunstância seja, ao mesmo tempo, a realização de um mal em si e realização do bem moral. Se é a realização do bem moral, então sua realização deve estar justificada. Mas, se a bondade dos fins que escolhemos para agir não é suficiente para justificar os meios que escolhemos para atingir esses fins, então não podemos mostrar que a realização de uma determinada ação é a realização do 
bem moral apenas apontando para o fim bom dessa ação. É claro que os fins que escolhemos, se são bons em si, justificam parcialmente os meios que escolhemos, as ações que deliberamos realizar. Todavia, a bondade dos fins, como já foi dito, não é suficiente para justificar os meios escolhidos para atingi-los. No caso em que alguém mata uma pessoa para salvar a vida de alguém que não merece ser morto por essa pessoa, o meio para se atingir o fim, matar uma pessoa, não pode ser justificado simplesmente porque o fim, salvar a vida de alguém que não merece morrer, é um bem em si. E se esse meio é um mal em si, como parece ser nesse caso, então a situação é ainda pior: como pode ser o caso que alguém esteja realizando o bem moral, se o que ela está efetivamente fazendo é realizar um mal em si, mesmo que seja para que o efeito disso seja um bem em si? Só há uma ação sendo realizada nessa circunstância: matar uma pessoa. Como ela pode ser a realização do bem moral, dado que ela é um mal em si e o seu fim é insuficiente para justifica-la?

O purismo moral, por sua vez, enfrenta o seguinte problema: muitas ações, que são o resultado de uma deliberação realizada com o máximo grau de excelência e são, de acordo com nossas intuições morais compartilhadas mais básicas, paradigmas de ações moralmente boas, são, de acordo com o purismo moral, moralmente más, pelo simples fato de que são a realização de um mal em si. O caso daquele que mata para salvar a vida de quem não merece morrer é um exemplo. O caso daquele que mente para salvar a vida de uma pessoa é outro exemplo. Como o resultado de uma deliberação realizada com o máximo grau de excelência pode ser uma má ação? Como o melhor a se fazer numa determinada circunstância pode ser uma má ação? Ou o melhor a fazer nesses casos não é matar ou mentir? O melhor seria assistir uma pessoa ser morta sem merecer, mesmo estando sob nosso poder evitar isso matando ou mentindo? Não estaríamos cometendo o erro da omissão, no primeiro caso, e de colaboração com um assassino, no segundo? Uma boa filosofia moral deve apresentar como justificadas aos menos aquelas ações que nos parecem ser os paradigmas de ações moralmente boas. Não parece que ter mais cuidado em preservar a vida de um assassino que e preservar a vida de sua vítima, ou ter mais cuidado em preservar a verdade que em preservar a vida de uma pessoa que não merece morrer sejam atitudes moralmente justificáveis.

O problema do casuísmo, por fim, é que ele não consegue acomodar nossas intuições morais compartilhadas mais básica sobre o que é um mal em si ou um bem em si. O casuísta não poderia, por exemplo, reprovar alguém que tem prazer em matar uma 
pessoa em circunstâncias em que fazer isso é a melhor coisa a ser feita, pois matar alguém não é, para ele, um mal em si, pela simples razão que nada o é. Mas isso fere nossa intuição moral segundo a qual certas ações, por mais que sejam nosso dever moral em certas circunstâncias, são em si mesmas moralmente indesejáveis, ou seja, são um mal em si. Compreendemos o que seria para uma pessoa desejar realizar o seu dever, tal como salvar a vida de alguém que não merece morrer, por exemplo, mesmo quando esse dever consiste em realizar um mal em si, tal como matar uma pessoa. Mas o que compreendemos é que ela deseje salvar a vida de alguém que não merece morrer, não que ela deseje matar alguém (e nisso o finalista está correto). Uma pessoa que sai feliz de casa porque está indo matar alguém, mesmo quando essa morte é moralmente justificada, nos parece moralmente repugnante. Mas um casuísta não poderia achar tal pessoa moralmente repugnante, porque para ele não há nada que seja um mal em si e, portanto, nada é em si mesmo moralmente repugnante.

\section{A melhor solução: o bem pode ser dito de diferentes modos}

Como já disse, concordo com o finalista que o conflito de intuições que constitui o problema do dever de se realizar o mal é um conflito meramente aparente, ilusório. Mas creio que o finalista fracassa em mostrar isso. O problema fundamental de todas as tentativas de solução examinadas acima é a suposição que os termos "bem"/"mal" e "bom"/"mau" estão sendo usado no mesmo sentido em frases como

(1) "Matar é mau",

(2) "Mentir é mau",

(3) "Mentir para salvar a vida de alguém que não merece morrer é realizar o bem",

(4) "Matar para salvar a vida de alguém que não merece morrer é realizar o bem".

Estas frases, entretanto, não expressam o mesmo tipo de juízo moral. As frases (1) e (2) expressam um tipo de juízo moral diferente daquele expresso pelas frases (3) e (4). As frases (1) e (2) expressam o que eu chamo de juizos sobre valores, enquanto as frases (3) e (4) expressam o que eu chamo de juízos de deliberação. Nas frases (1)-(4), portanto, os termos "bem"/"mal" e "bom"/"mau" não estão sendo usado no mesmo sentido. Vejamos como entendo a natureza de cada um desses tipos de juízos morais e, 
portanto, qual é a diferença de sentido que julgo ser decisiva para resolver o problema do dever de realizar o mal.

Os juízos sobre valores são juízos sobre tipos de ações, por oposição a ações concretas que realizamos sempre em determinadas circunstâncias. Nesses juízos determinamos quais ações são, em si mesmas, boas ou más. Uma ação é em si mesma boa ou má quando ela assim o é independentemente das circunstâncias em que ela é realizada. Se matar, por exemplo, é uma ação em si mesma má, então uma ação desse tipo é má independentemente das circunstâncias em que ela é realizada. Quando estamos julgando se ações de um certo tipo são ou não são más (em si mesmas), estamos tentando determinar se elas são ou não são moralmente desejáveis em si mesmas. E a propriedade de ser moralmente desejável pode ser apresentada em termos de obrigações, permissões e factibilidades circunstanciais de mundos possíveis. Ações de um certo tipo são moralmente desejáveis (em si mesmas boas) quando um mundo possível em que tais ações são factíveis e permitidas em certas circunstâncias é melhor que um outro mundo possível em que em nenhuma circunstância tais ações são permitidas ou factíveis. Ações de um certo tipo são moralmente indesejáveis (em si mesmas más) quando um mundo possível em que tais ações são factíveis e obrigatórias em certas circunstâncias é pior que um outro mundo possível em que em nenhuma circunstância tais ações são obrigatórias ou factíveis.

Juízos sobre valores determinam a direção moral que queremos que o mundo tome quando queremos transformá-lo num mundo moralmente melhor. Quando queremos essa transformação, queremos modificar as circunstâncias em que as pessoas deliberam para agir, de tal forma que ações más em si nunca sejam obrigações e ações boas em si nunca sejam proibições. Todavia, juízos sobre valores não implicam nada sobre qual ação é moralmente a melhor possível de ser realizada em cada circunstância. Mesmo que matar seja um mal em si, por exemplo, disso não se segue que matar não possa ser moralmente a melhor ação possível de ser realizada em uma determinada circunstância; portanto, não se segue que matar não seja o dever moral em uma determinada circunstância. Ser um mal em si não é o mesmo que ser o que não devemos fazer em qualquer circunstância. A deliberação sobre qual ação é moralmente a melhor possível de ser realizada em determinada circunstância não consiste num procedimento algorítmico baseado tão somente sobre o que julgamos serem tipos de ações em si mesmas boas e más e cujo resultado é sempre uma ação em si mesma boa. O melhor a 
ser feito em certa circunstância pode muito bem ser algo que é um mal em si. Esse é justamente o outro sentido de "bem"/"bom que constitui o sentido das frases (3) e (4): uma ação concreta é a realização do bem moral, nesse sentido, quando é moralmente a melhor ação possível de ser realizada numa certa circunstância. Dizer que essa ação concreta é a realização do bem moral, nesse sentido, portanto, não contradiz a afirmação de que uma ação desse tipo é um mal em si. Ela é o tipo de ação que desejaríamos não ter de realizar, embora seja o que devemos realizar na circunstância em questão. Preferimos que o mundo não contivesse uma circunstância em que realizar essa ação é uma obrigação, mas reconhecemos justamente que, nessa circunstância, ela é uma obrigação, pois é o melhor que podemos fazer nela. Uma ação desse tipo é um mal em si, mas essa ação concreta é o bem que podemos realizar nessa circunstância.

De acordo com essa análise, portanto, não há nenhuma contradição em se dizer de uma determinada ação concreta que ela é do tipo de ação que é um mal em si (é moralmente indesejável) e, ao mesmo tempo, que é a realização do bem moral na circunstância em que é realizada (é moralmente o melhor a ser feito nessa circunstância). O que justifica a realização dessa ação nessa circunstância não é apenas a bondade do fim para o qual ela é realizada, mas o fato de que não há nenhuma opção de ação factível melhor. Esse resultado está de acordo com nossas práticas ordinárias de deliberar moralmente: como foi dito no início, muitas vezes lamentamos porque o melhor a se fazer em certas circunstâncias é aquilo que é dos males o menor. Entre permitir que uma pessoa que não merece morrer seja morta e matar o seu potencial assassino, ambos males em si, quando não há outro meio para salvar a vida da vítima, escolhemos realizar, com pesar, o mal menor. Não obstante, a realização do mal menor é a realização do bem moral, pois é o resultado da deliberação excelente.

Agora podemos ver mais claramente a diferença entre uma ação absolutamente boa ou má e uma ação boa ou má em si. O que é um tipo de ação absolutamente má, diferentemente das ações más em si, jamais pode ser uma ação concreta boa em nenhuma circunstância. A idéia de bem e mal absolutos nasce justamente do mal entendimento da independência do bem e mal em si em relação às circunstâncias. Um tipo de ação que é má em si assim o é independentemente das circunstâncias. Mas disso não se segue que uma instância desse tipo não possa ser a realização do bem em determinada circunstância. Segue-se apenas que em nenhuma circunstância esse tipo de ação é boa. 
Dado que se tratam de dois sentidos de "bem" nas frases (1) e (2), por um lado, e (3) e (4), por outro, são diferentes os paradigmas que fixam esses sentidos. No primeiro caso, trata-se de paradigmas de tipos de ações moralmente desejáveis. No segundo caso trata-se de paradigmas de deliberações sobre o que é melhor fazer em determinadas circunstâncias. Sendo assim, são também diferentes os enunciados gramaticais que enunciam as regras de uso de tais termos. "Matar não é um bem" é um exemplo do primeiro tipo. "O bem pode ser o menor dos males" é um exemplo do segundo tipo.

\section{Objeções e respostas}

Alguém poderia objetar que a solução do problema não está em admitir dois sentidos de "bem", mas em mostrar que nem sempre o melhor a fazer é um bem moral e que uma pessoa moralmente boa não é aquela que realiza em geral o bem, mas é aquela que sempre faz o melhor em cada circunstância, aquela que realiza o seu dever. Quero chamar essa solução de deontologismo.

O problema do deontologismo é que ele não acomoda o caso da pessoa desafortunada descrita no início desse texto. Se ela é de tal forma desafortunada que, em todas as circunstâncias em que ela precisa agir, o melhor a fazer é sempre um mal em si, e se, por isso, de acordo com o deontologismo, ela não realiza o bem moral, em nenhum sentido de "bem", então, se essa pessoa é moralmente boa, ela o é tão somente porque realiza o mal moral e o realiza porque assim deve fazê-lo. Mas como alguém pode ser bom porque realiza o mal moral, sem realizar o bem moral? E como pode ser um dever moral realizar o mal moral? Essas consequências contra-intuitivas do deontologismo originam-se da suposição de que o melhor a fazer em uma dada circunstância não é um bem moral em nenhum sentido moral de "bem". Ordinariamente, consideramos que toda ação que é resultado de uma deliberação moral excelente é um bem moral. Isso se mostra no uso de frases como "Agiste bem", mesmo quando se trata de uma ação que, em si mesma, é o menor dos males. Nesse caso, ninguém retrucaria dizendo: "Não agi bem, não! Afinal, o que realizei é um mal em si." Ninguém retrucaria assim porque quando alguém julga que se agiu bem, o que está julgando não é o tipo de ação que foi realizada, mas tão somente a ação concreta realizada numa determinada circunstância.

Alguém poderia objetar que embora o fato que uma determinada ação é o melhor a ser feito numa determinada circunstância não exclua a possibilidade de que realizar essa ação seja um bem moral, ele não implica que se trata de um bem moral. Em 
algumas circunstâncias em que as melhores opções de ações factíveis são males em si, os males são em grau tão alto que não podem ser um bem moral. De acordo com essa objeção, minha solução estaria baseada na falsa identidade entre o que é o melhor a ser feito numa determinada circunstância e o que é o bem moral que podemos realizar. Nem sempre o que é o melhor a ser feito numa determinada circunstância é um bem moral.

Todavia, minha solução não depende dessa tese, seja ela verdadeira, seja falsa. Tudo que minha solução implica é que haja um sentido moral de "bem" que qualifica ações particulares como as melhores coisas a serem feitas em determinadas circunstâncias, mesmo quando, em alguns casos, se trata de uma ação que é um mal em si. Tudo que necessito é que uma ação concreta possa satisfazer as seguintes três condições em alguma circunstância:

(a) ser o melhor a fazer na circunstância C

(b) ser um mal em si

(c) ser a realização do bem moral

A satisfação da condição (a) não implica a satisfação da condição (c). Tudo que preciso é que a satisfação da condição (b) tampouco implique a impossibilidade de satisfação da condição (c). Notem que eu disse que um enunciado gramatical que enuncia uma regra de uso de "bem" nas frases (3) e (4) é "O bem pode ser o menor dos males". Eu estaria baseando minha solução naquela falsa identidade entre o que é o melhor a se fazer em uma certa circunstância e o bem moral que podemos realizar se tivesse dito que "O menor dos males é um bem moral" é um enunciado gramatical. Minha solução não almeja solucionar também os dilemas morais e não depende de que eles sejam solucionados. Basta para mim que nem todas as circunstâncias de deliberação apresentem dilemas morais.

Alguém poderia objetar que não há justificação epistemicamente suficiente para a afirmação de que um certo tipo de ação é um bem ou um mal em si e que, por isso, minha solução para o problema do dever de realizar o mal não pode ser justificada, na medida em que a justificação da minha solução dependeria da existência de uma justificação epistemicamente suficiente para a afirmação de que um certo tipo de ação é um bem ou um mal em si. Todavia, minha solução não depende da existência de uma tal justificação. O problema que eu abordo consiste numa aparente incompatibilidade entre 
algumas de nossas intuições morais, sejam elas justificadas ou não. A solução consiste em mostrar que, a despeito da aparência, tais intuições não são incompatíveis, sejam elas justificadas ou não. Se algumas delas não forem justificadas, tal como a crença de que alguns tipos de ações são boas em si e que outros tipos de ações são más em si, então talvez tenhamos que fazer uma reforma no nosso sistema de crenças morais. Mas, isso não invalida em nada a minha solução para o problema. O problema é sobre relações lógico-conceituais entre algumas de nossas intuições morais, não um problema epistêmico, sobre a justificação dessas intuições.

Um ponto adicional sobre essa objeção deve ser mencionado aqui para fins de clareza: seja qual for o argumento contra a existência de uma justificação epistemicamente suficiente para a afirmação de que um certo tipo de ação é um bem ou um mal em si, se ele for dirigido contra a existência de uma justificação epistemicamente suficiente para a afirmação de que um certo tipo de ação é um bem ou um mal absolutos, então ele erra o alvo.

\section{História}

A análise sobre a qual se baseia a solução que apresentei para o problema do dever de realizar o mal é bastante semelhante, para se dizer o mínimo, a algumas análises que Aristóteles apresenta na sua Ética a Nicômaco. Digo isso porque não quero reivindicar originalidade sobre isso, embora acredite que Aristóteles não tenha apresentado sua análise como uma base para a solução do referido problema. Aristóteles claramente sustenta que, em algumas circunstâncias, o resultado da deliberação excelente é uma ação que é o menor dos males (ARISTÓTELES, 1113b 20-14). Além disso ele faz uma distinção análoga à minha distinção entre juízos de valor e juízos de deliberação. Os juízos de valor, segundo ele, são aqueles por meio dos quais iniciamos a deliberação (ARISTÓTELES, 1144a 31). Os valores são aqueles tipos de ações que são intrinsecamente boas, cuja realização repetida constitui os bons hábitos, e cujo conhecimento é uma condição necessária, segundo Aristóteles, não apenas para que alguém realize boas ações, mas também para que alguém possa compreender suas reflexões éticas (ARISTÓTELES, 1095b 4-5). ${ }^{3}$

Os bons hábitos também são aquilo por meio do qual a investigação em ética se inicia, pois toda investigação, segundo Aristóteles, se inicia pelo que é mais bem conhecido. Os bons hábitos são bem conhecidos como tais porque são aquilo pelo qual a 
educação ética se inicia. Creio que esse ponto se aproxima de uma análise wittgensteiniana do aprendizado ético. $\mathrm{O}$ aprendizado ético se dá por meio de exemplos paradigmáticos de tipos de ações intrinsecamente boas (e consequentemente, de tipos de ações intrinsecamente más). Esses tipos ações intrinsecamente boas são os bons hábitos. Eles são o que há de mais bem conhecido no início da investigação ética justamente porque são os exemplos paradigmáticos que determinam o significado de "boa ação", quando aplicado a tipos de ações. Isso talvez explique por que Aristóteles diz que alguém que não fosse educado nos bons hábitos sequer conseguiria entender o que ele diz na investigação ética. Tal pessoa não teria adquirido os conceitos básicos para iniciar a investigação. 


\section{Notas:}

${ }^{1}$ Professor do Departamento de Filosofia e do Programa de Pós-Graduação em Filosofia da Universidade Federal do Paraná (UFPR), Curitiba, P. R., Brasil. E-mail: alexandre.n.machado.ufpr@gmail.com

${ }^{2}$ A percepção desse problema, na forma em que eles está apresentado aqui, me ocorreu pela primeira vez assistindo a uma palestra do meu colega Darlei Dall'agnol. Agradeço a Guilherme Ghizoni por valiosa discussão sobre as principais idéias contidas numa primeira versão desse texto, publicada no meu blog Problemas Filosóficos: http://problemasfilosoficos.blogspot.com.br/2013/03/bem-em-si-e-o-bem-quepodemos-realizar.html Também agradeço a Edy Klévia Fraga de Souza por valiosas discussões durante a redação da presente versão desse texto.

${ }^{3}$ Aristóteles já percebia as bases éticas do trabalho cognitivo: “...é preciso cultivar primeiro a alma do estudioso por meio de hábitos, tornando-o capaz de nobres alegrias e nobres aversões, como se prepara a terra que deve nutrir a semente. Com efeito, o que se deixa dirigir pela paixão não ouvirá o argumento que o dissuade; e, se o ouvir, não o compreenderá." (Aristóteles, 1179b 24-26) 


\section{Referências}

ARISTÓTELES. Ética a Nicômaco. trad. Leonel Vallandro e Gerd Bornheim, São Paulo: Abril Cultural, 1979.

WITTGENSTEIN, L. Philosophical Investigations. trad. G.E.M. Anscombe. Oxford: Blackwell, 1958. 